\title{
Small extra ring chromosome derived from chromosome 10p: clinical report and characterisation by FISH
}

\author{
Elisabeth Blennow, Elsa Tillberg
}

\begin{abstract}
We present a case with a small extra ring chromosome which was found in $66 \%$ of lymphocytes on routine cytogenetic examination. FISH analyses, using centromere specific and single copy probes, showed that the extra ring chromosome was derived from the most proximal part of $10 \mathrm{p}$, close to the centromere. The patient has a unilateral cleft lip and palate, mild dysmorphic features, and mild mental retardation. Only a limited number of extra ring chromosomes have been characterised so far. To our knowledge, this is the first reported patient with an extra ring chromosome derived from chromosome 10 p.

(f Med Genet 1996;33:399-402)
\end{abstract}

Key words: extra ring chromosome; fluorescence in situ hybridisation; chromosome 10 .

Since the early days of human cytogenetics there have been reports of constitutional extra chromosomes with no direct equivalent among normal chromosomes. These chromosomes have highly variable characteristics and phenotypic implications. They have often been referred to as marker chromosomes, as well as "supernumerary" or "accessory" chromosomes. In order to avoid ambiguity, Hook and Cross" coined the term "extra structurally abnormal chromosome" (ESAC). The incidence of ESACs has been estimated to be 0.14 to 0.72 per 1000 newborns $^{2-5}$ and 0.65 to 1.5 per 1000 fetuses in prenatal studies. ${ }^{16-10}$

Small extra ring chromosomes constitute approximately $10 \%$ of all ESACs ${ }^{10}$ and represent the most poorly characterised group. Firstly, ring chromosomes are often unstable, giving rise to different degrees of mosaicism, making the analyses more difficult to perform and to interpret. Secondly, an extra ring chromosome may originate from any of the human chromosomes and it is seldom possible to establish the origin by routine cytogenetic methods. Using fluorescence in situ hybridisation (FISH), the chromosomal origin may be identified. Up to now, the origins of approximately 40 extra ring chromosomes have been published but only a few cases have been reported to be derived from the same chromosome (table), ${ }^{11-26}$ and some chromosomes have so far never been described as the origin of an extra ring chromosome. Thirdly, only the origin of the centromere or the whole chromosome has been reported to date, thereby leaving many alternative variants of rings for each chromosome, for example, $\mathrm{p}$ or $\mathrm{q}$ arm involvement. Considering all these facts, one has to be very cautious when making phenotypic correlations. This makes counselling complicated, especially in prenatal cases. The situation may be improved by more detailed characterisation of the extra ring chromosomes, thereby making it possible to identify cases with similar chromosomal defects that may have comparable phenotypic implications.

\section{Material and methods \\ CASE REPORT}

The patient was the first child of healthy, nonconsanguineous parents. The father had four healthy children with another woman. During the first trimester, the mother noted vaginal bleeding which later ceased and the pregnancy was considered to be normal thereafter. The patient was born after 41 weeks of gestation. He was small for dates with a birth weight of $2300 \mathrm{~g}$ and a birth length of $48 \mathrm{~cm}$; he had a unilateral cleft lip and palate. The patient was raised in Peru until he was 15 years old so early detailed clinical information is lacking. Initial gross motor development was within the normal range. However, mental development was late and he attended a school for mentally retarded children from the age of 5 years. At 15 years of age, the patient first visited a paediatric clinic in Sweden. He was $153 \mathrm{~cm}$ tall (-3 SD) and was microcephalic with a head circumference of $51 \mathrm{~cm}(-2 \mathrm{SD})$. Some mild dysmorphic features were noted, for example, low set ears with a prominent anthelix and micrognathia (fig 1). The canthal index was at the upper limit of normal (38) and the eyes had a mild upward slant. There was general muscular weakness with predominantly upper limb hypotonia. His personality was immature but pleasant. Medical investigation, including a CT scan of the brain and an EEG, was normal. Psychological testing (WISC) indicated mild mental retardation with an IQ of approximately 70. Chromosome analysis showed the karyotype $46, \mathrm{XY} / 47, \mathrm{XY},+\mathrm{r}$, with the extra ring chromosome present in $66 \%$ of lymphocytes. The mother's karyotype was normal. The father was not available for testing.

\section{CYTOGENETIC STUDIES}

Metaphase slides were prepared from lymphocyte cultures. QFQ banding was performed using standard procedures. 
Extra ring chromosomes, their origin, and associated phenotypic findings

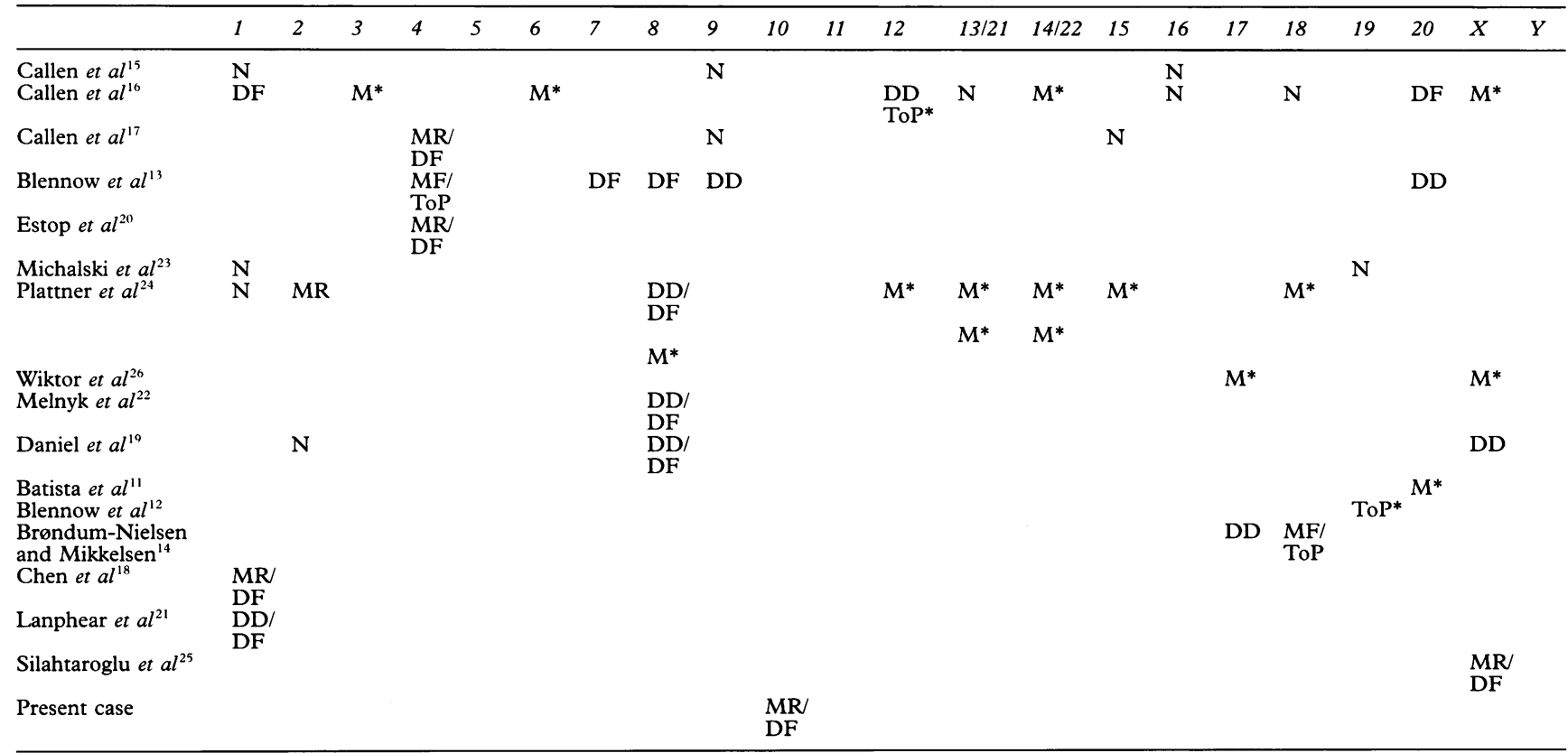

* Phenotype cannot be evaluated, $\mathrm{M}=$ multiple extra chromosomes, $\mathrm{N}=$ normal, $\mathrm{DD}=$ developmental delay, $\mathrm{MR}=\mathrm{mental}$ retardation, $\mathrm{DF}=$ dysmorphic features, $\mathrm{MF}=$ malformations, $\mathrm{ToP}=$ termination of pregnancy.

FISH

The chromosome slides were fixed in methanol: acetic acid (3:1) for 40 minutes, in acetone for 10 minutes, and then air dried. Centromere specific probes from all human chromosomes were used. A list of these probes, their origin, and use has been previously published. ${ }^{12}$ The cosmids were labelled with biotin-16-dUTP by nick translation. They had been located close to the centromere on 10p11.2 (JC2108 and JC2139) and 10q11.2 (JC2001 and JC2164). ${ }^{27}$ The chromosome specific library PCR-10 and the cosmids were hybridised in $50 \%$ formamide, $2 \times \mathrm{SSC}, 50 \mathrm{mmol} / \mathrm{l}$ phosphate buffer, $\mathrm{pH} 7 \cdot 0$, at a probe concentration of $4-5 \mathrm{ng} / \mu \mathrm{l}$. In addition, 2-3 mg Cot-1 DNA (BRL) was added to the probe mixture. After denaturation at $75^{\circ} \mathrm{C}$ for five minutes, the probe mixture was left to prehybridise at $37^{\circ} \mathrm{C}$ for one hour.

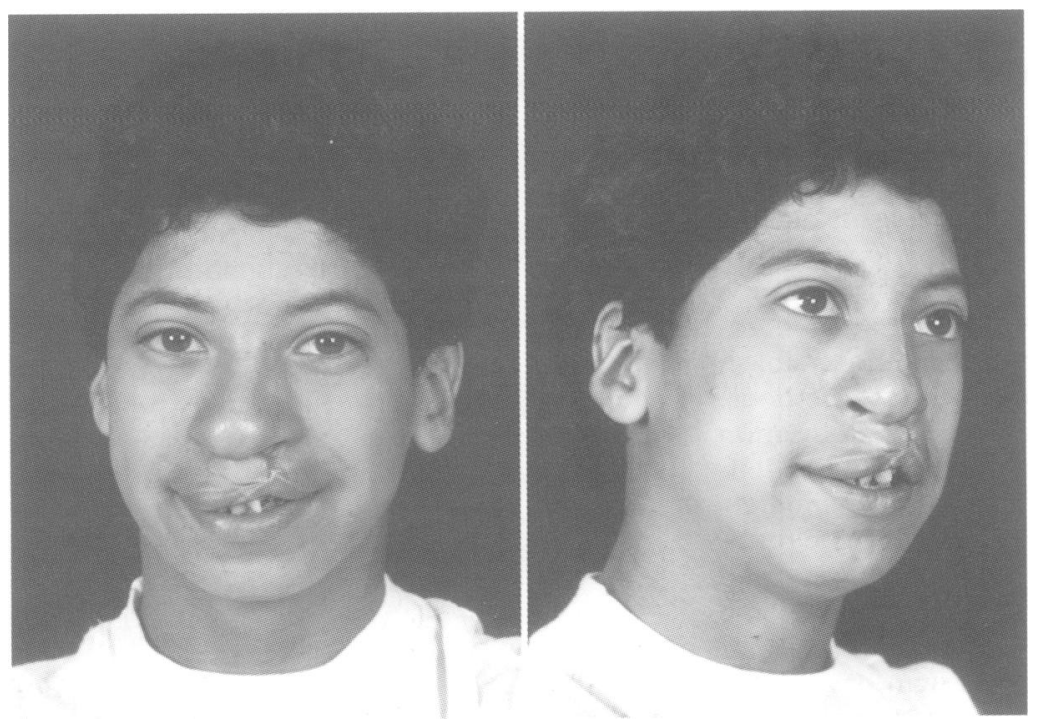

Figure 1 The patient at 16 years of age.
Hybridisation was performed in a moist chamber at $37-41^{\circ} \mathrm{C}$ overnight. The slides were then washed three times for five minutes in $50 \%$ formamide, $2 \times \mathrm{SSC}$ at $42^{\circ} \mathrm{C}$ and twice in $2 \times \mathrm{SSC}$ at $42^{\circ} \mathrm{C}$ (the cosmids once for five minutes in $2 \times \mathrm{SSC}$ at $72^{\circ} \mathrm{C}$ ).

Probe detection and signal amplification were performed by applying two alternating layers of fluorescein-avidin DCS (Vector Lab) and biotinylated anti-avidin antibodies (Vector Lab). After dehydration, the slides were mounted in glycerol containing $2 \cdot 3 \%$ DABCO $(1,4-$ diazabicyclo- $(2,2,2)$ octane) as antifade, and DAPI (4,6-diamino-2-phenyl-indole) at $0.5 \mu \mathrm{g}$ / $\mathrm{ml}$ as counterstain.

The signal was visualised using a Zeiss Axiophot fluorescence microscope equipped with cooled CCD camera (Photometrics Nu 200/ $\mathrm{CH}$ 250), controlled by a Macintosh Quadra 950 computer. Gray scale images were captured, pseudocoloured, and merged using the SmartCapture software (Digital Scientific, Cambridge).

\section{Results}

Cytogenetic studies showed a small extra ring chromosome in $66 \%(19 / 29)$ of the lymphocytes. No specific banding pattern indicating the origin of the ESAC could be detected (fig $2 \mathrm{~d}, \mathrm{f}$ )

FISH using centromere specific probes four by four, as described in Blennow et al,,$^{13}$ showed labelling of the ESAC when using probes from chromosomes 7, 8, 9, and 10. Hybridisation using these four probes separately showed a centromere 10 origin (fig 2a). This was confirmed by using a chromosome 10 specific library which labelled the whole ring chromosome, thereby excluding the involvement of any other chromosome (fig 2b). Single copy probes localised to chromosome $10 \mathrm{p} 11.2$ 

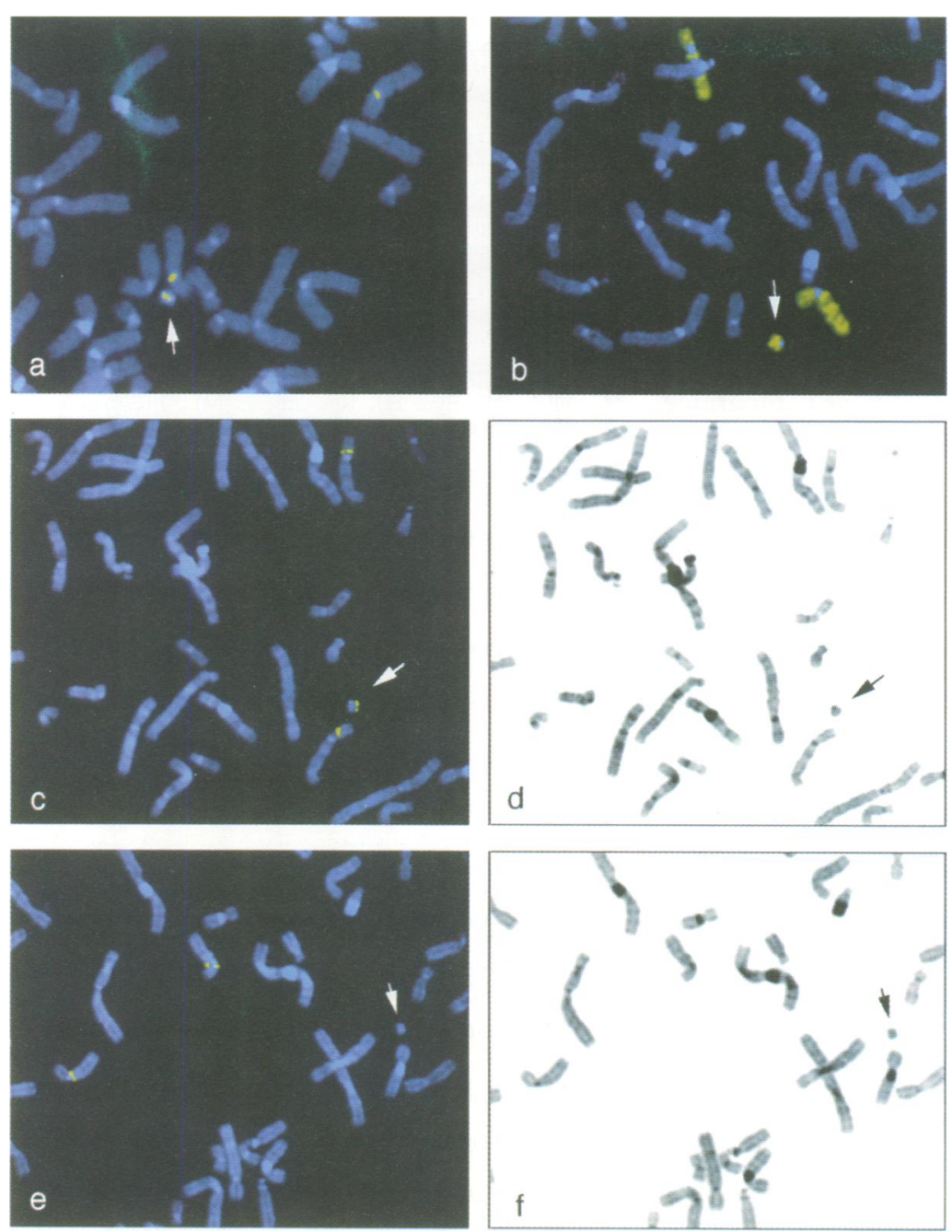

Figure 2 FISH on partial metaphases from the patient: (a) using a centromere 10 specific probe (D10Z1) which gives a signal on the ring chromosome as well as two normal chromosomes 10; (b) using a chromosome 10 specific library (PCR-10), which labels the whole ring chromosome; (c) using two single copy probes localised close to the

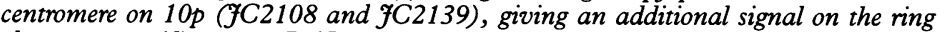
chromosome; (d) reverse DAPI banding of the metaphase in fig $2 c ;(e)$ using two single

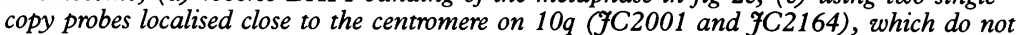
label the ring chromosome; $(f)$ reverse DAPI banding of the metaphase in fig $2 e$.

(JC2108 and JC2139) and 10q11.2 (JC2001 and JC2164) were used separately in order to delineate the ESAC in detail. JC2108 and JC2139 labelled the ESAC but JC2001 and JC2164 did not (fig 2c, e). This indicates that the ESAC is composed predominantly of material from proximal $10 \mathrm{p}$.

\section{Discussion}

We present here the study of a small extra ring chromosome found in a boy with a cleft lip and palate, mild dysmorphic features, and mild mental retardation. Small extra ring chromosomes have previously been described originating from almost all human chromosomes with the exception of chromosomes $5,10,11$, 22 , and $\mathrm{Y}$ (table). ${ }^{11-26}$ In most cases, the origin was determined by FISH using centromere specific probes or chromosome specific libraries. Multiple rings or other extra chromosomes were found in $22 \%$ of the cases, making phenotypic correlations unreliable. Two of the 33 single cases were diagnosed prenatally and the phenotype could not be assessed at termination. A normal phenotype was found in 12 out of the remaining 31 cases $(\approx 40 \%)$. In six of these, DA/DAPI staining was performed and was found to be positive. In only one case could positive DA/DAPI staining be linked to an abnormal phenotype. ${ }^{21}$ In 19 out of 31 cases $(\approx 60 \%)$, an abnormal phenotype was found, and in four of these the symptoms consisted of dysmorphic features alone. The remaining patients had various symptoms, the most common being developmental delay. Some extra ring chromosomes were derived from the same chromosome, but in spite of the same origin, a great variation in phenotype was observed among these patients.

There may be several explanations for this observation. (1) Owing to the general mitotic instability of ring chromosomes, aneuploid and rearranged cells are often found in ring carriers, creating the possibility of variation in phenotypic expression. (2) The frequency of the extra ring chromosome, that is, the degree of mosaicism, in different patients as well as in different tissues in the same patient may vary and is hard to establish. (3) The ascertainment may cause interpretation problems. Most ring chromosomes are ascertained in phenotypically abnormal subjects, but it is not always possible to correlate the phenotype with the presence of the extra chromosome. (4) In some cases, the symptoms may be caused by uniparental disomy and not the trisomy caused by the ESAC itself. There have been indications that the presence of an ESAC increases the probability of non-disjunction and uniparental disomy has been found in patients with de novo ESACs. ${ }^{2829}$ (5) The ring chromosome may be derived from unequal parts of the $\mathrm{q}$ arm, the $\mathrm{p}$ arm, or small parts of both arms. According to a previously published theory, ${ }^{14}$ the small extra ring chromosomes are formed by a break at, or very close to, the centromere in the region containing alphoid repeats and another on the $\mathrm{p}$ or the $\mathrm{q}$ arm, thereby creating small ring chromosomes that are either $\mathrm{p}$ or $\mathrm{q}$ derived. This theory has been supported by the fact that patients with ring chromosomes which are derived from chromosomes 1 and 9 are phenotypically normal when the rings are DA/ DAPI positive (indicating involvement of the heterochromatic q arm), but show symptoms when they are DA/DAPI negative (excluding q arm involvement). Nevertheless, the case reported by Lanphear et $a l^{21}$ had a DA/DAPI positive extra ring chromosome derived from chromosome 1 which was associated with developmental delay and dysmorphic features. This implies that, in spite of the apparent common origin, different breakpoints may be involved in the formation of every ring chromosome and each new case has to be considered unique. This is also supported by a recent publication by Feng et al ${ }^{30}$ where the detailed origin of two extra ring chromosomes, previously shown to be derived from chromosome $4,{ }^{1720}$ was established. One of them was shown to originate from the proximal part of the q arm alone, while the other ring chromosome was formed by a complex rearrange- 
ment including three discontinuous regions on chromosome 4 . This illustrates the absolute need for detailed characterisation of ESACs before making any attempt to ascertain common phenotypes. In the present case, the extra ring chromosome was shown to be predominantly derived from the most proximal part of the $\mathrm{p}$ arm on chromosome 10 .

At present, the only way to characterise small extra ring chromosomes further is to pinpoint the origin in detail using single copy probes or reverse painting. Patients who have comparable chromosome defects may thereby be recognised, giving the possibility of identifying similarities in the clinical picture that will benefit the counselling of future cases.

We thank Lena Ljöstad and Lena Tudegård for expert technical assistance and Drs J W Gray and J-i Mao for generously supplying the PCR library and the cosmid probes, respectively. supplying the PCR library and the cosmid probes, respectively. This work

1 Hook EB, Cross PK. Extra structurally abnormal chromosomes (ESAC) detected at amniocentesis: frequency in approximately 75,000 prenatal cytogenetic diagnoses and association with maternal and paternal age. $A m \mathcal{F}$ Hum Genet 1987;40:83-101.

2 Nielsen J, Wohlert M. Chromosome abnormalities found among 34,910 newborn children: results from a 13-year incidence study in Arhus, Denmark. Hum Genet 1991;87: $81-3$.

3 Nielsen J, Rasmussen K. Extra marker chromosome in newborn children. Hereditas 1975;81:221 -4

4 Jacobs PA, Melville M, Ratcliffe S. A cytogenetic survey of 11,680 newborn infants. Ann Hum Genet 1974;37:359-67.

5 Hamerton JL, Canning N, Ray M, Smith S. A cytogenetic survey of 14,069 newborn infants. I. Incidence of chromosome abnormalities. Clin Genet 1975;8:223-43.

6 Ferguson-Smith MA, Yates JRW. Maternal age specific rates for chromosome aberrations and factors influencing them: report of a collaborative European study on $52965 \mathrm{am}$ niocenteses. Prenat Diagn 1984;4:5-44.

7 Sachs ES, van Hemel JO, den Hollander JC, Jahoda MGJ. Marker chromosomes in a series of 10000 prenatal diagnosis. Cytogenetic and follow up studies. Prenat Diagn 1987;7:81-9.

8 Warburton D. Outcome of cases of de novo structural rearrangements diagnosed at amniocentesis. Prenat Diagn 1984;4:69-80.

9 Warburton D. De novo balanced chromosome rearrangements and extra marker chromosomes identified at prenatal diagnosis: clinical significance and distribution of breakpoints. Am ₹ Hum Genet 1991;49:995-1013.

0 Blennow E, Bui TH, Kristoffersson U, et al. Swedish survey on extra structurally abnormal chromosomes in 39105 consecutive prenatal diagnoses: prevalence and characterization by fluorescence in situ hybridization. Prenat Diagn 1994;14:1019-28.

11 Batista DAS, Escallon C, Blakemore KJ, Stetten G. An accessory marker derived from chromosome 20 and its co-existence with a mosaic trisomy 20 cell line. Prenat Diagn 1995;15:123-7.
12 Blennow E, Brøndum Nielsen K, Telenius H, et al. 50 probands with extra structurally abnormal chromosomes characterized by fluorescence in situ hybridization. $A m \mathcal{F}$ Med Genet 1995;55:85-94.

13 Blennow E, Annerén G, Bui TH, Berggren E, Asadi E, Nordenskjöld $M$. Characterization of supernumerary ring marker chromosomes by fluorescence in situ hybridization. Am F Hum Genet 1993;53:433-42.

14 Brøndum-Nielsen K, Mikkelsen M. A 10-year survey, 19801990 , of prenatally diagnosed small supernumerary marker chromosomes, identified by FISH analysis. Outcome and follow-up of 14 cases diagnosed in a series of 12699 and follow-up of 14 cases diagnosed in a series of

15 Callen DF, Ringenbergs ML, Fowler JCS, Freemantle CJ, Haan EA. Small marker chromosomes in man: origin from pericentric heterochromatin of chromosomes 1,9 , and 16. F Med Genet 1990;27:155-9.

16 Callen DF, Eyre HJ, Ringenbergs ML, Freemantle CJ, Woodroffe P, Haan EA. Chromosomal origin of small ring marker chromosomes in man: characterization by molecular genetics. Am ₹ Hum Genet 1991;48:769-82.

17 Callen DF, Eyre H, Yip MY, Freemantle J, Haan EA. Molecular cytogenetic and clinical studies of 42 patients with marker chromosomes. Am f Med Genet 1992;43: 709-15.

18 Chen H, Tuck-Muller CM, Batista DAS, Wertelecki W. Identification of supernumerary ring chromosome 1 moIdentification of supernumerary ring chromosome $1 \mathrm{mo}-$ Genet 1995:56:219-23.

19 Daniel A, Malafiej P, Preece K, Chia N, Nelson J, Smith M. Identification of marker chromosomes in thirteen patients using FISH probing. Am $\mathcal{F}$ Med Genet 1994;53:8-18.

20 Estop AM, LeChien KA, Sherer C, McPherson E, Clemens $M$, Cieply K. Genotype-phenotype correlations in patients with marker chromosomes and uncharacterized chromosome rearrangements. Cytogenet Cell Genet 1993;63: 254

21 Lanphear N, Lamb A, Oppenheimer S, Soukup S. Supernumerary chromosome marker (1) in a developmentally delayed child. Am 7 Med Genet 1995;57:400-2.

22 Melnyk AR, Dewald G. Identification of a small supernumerary ring chromosome 8 by fluorescent in situ pernumerary ring chromosome 8 by fluorescent in situ minor anomalies. Am f Med Genet 1994;50:12-4.

23 Michalski K, Rauer M, Williamson N, Perszyk A, Hoo JJ. Identification, counselling, and outcome of two cases of prenatally diagnosed supernumerary small ring chromosomes. Am $\mathcal{F}$ Med Genet 1993;46:88-94.

4 Plattner R, Heerema NA, Howard-Peebles PN, Miles JH, Soukup S, Palmer CG. Clinical findings in patients with marker chromosomes identified by fluorescence in situ hybridization. Hum Genet 1993;91:589-98.

25 Silahtaroglu AN, Hacihanefioglu S, Yilmaz S, Tarkan Y, Cenani A, Tümer Z. A small supernumerary marker chromosome X identified by in situ hybridization. Clin Genet 1995;47:270-3

26 Wiktor A, Van DD, Weiss L Characterization of a de novo $48, \mathrm{XX},+\mathrm{r}(\mathrm{X}),+\mathrm{r}(17)$ by in situ hybridization in a patient $48, \mathrm{XX},+\mathrm{r}(\mathrm{X}),+\mathrm{r}(17)$ by in situ hybridization in a patient
with neurofibromatosis (NF1). Am 7 Med Genet 1993;45: $22-4$.

27 Zheng CJ, Ma NS, Dorman TE, et al. Development of 124 sequence-tagged sites and cytogenetic localization of 217 cosmids for human chromosome 10. Genomics 1994;22: 55-67.

28 Robinson WP, Wagstaff J, Bernasconi F, et al. Uniparental disomy explains the occurrence of the Angelman or PraderWilli syndrome in patients with an additional small inv dup(15) chromosome. F Med Genet 1993;30:756-60.

29 Temple K, James RS, Crolla JA, et al. An imprinted gene(s) for diabetes? Nature Genet 1995;9:110-12.

30 Feng YY, Eyre HJ, Bohlander SK, et al. Mechanisms of small ring formation suggested by the molecular characterization of two small accessory ring chromosomes derived from chromosome 4. Am f Hum Genet 1995;57: $1137-42$. 